\title{
Modeling and controlling for hydraulic excavator's arm
}

\author{
Daqing Zhang, Qinghua He, Peng Hao, HaiTao Zhang
}

\begin{abstract}
A bstract-Controlling of excavator's arm is an important and basic task in autonomous research of hydraulic excavator at present, but the behavior of the excavator's arm is dominated by the nonlinear dynamics of the hydraulic actuators. To find a feasible way to control excavator's arm and realize autonomous excavation, firstly, Full kinematic and dynamic models of the excavator arm, regarded as a planar manipulator with three degrees (boom, dipper and bucket) of freedom, were derived, the exponential product formula based on screw theory was used in kinematic model, by which objective angular series of the working mechanism was connected with the desired trajectory of the bucket, and the Lagrange equation was used in dynamic model. secondly, because the experimental excavator's L UDV hydraulic system was not fit for computer control, so the excavator was retrofitted with electrohydraulic proportional valves, associated sensors (three inclinometers), and a computer control system(the motion controller of EPE C), the retrofitted excavator could allow experimental evaluation and refinement of the developed controllers, then ,the full nonlinear math model of electrohydraulic proportional system was achieved; These models included detailed representation of the electrohydraulic actuation system to obtain structural insight into the dynamic behavior of the system; thirdly, According to the highly system dynamic, and parameters uncertainties, external disturbance, the dead region and nonlinear gain coefficient of the proportional direction valve, this paper presents a discontinuous projection based on an adaptive robust controller to approximate the nonlinear gain coefficient of the valve and the nonlinear of the whole system, the error is deal with robust feedback and an adaptive robust controller was designed. Finally, the experiment of the boom motion control is presented to illustrate the feasibility. The thesis covered some phases from modeling to theoretical analysis of controller designs, and to implementation and experimental validation of the new control schemes. These efforts had resulted in new control design methodologies that were applicable to several hydraulic proportional systems when high control performance is required in the presence of severe nonlinearity and uncertainty.
\end{abstract}

Index Tems- adaptive robust control, autonomous excavation, dynamic model, hydraulic excavator, kinematic model, motion control

This work was supported by the National Hi-Tech Research and Development Program(863) of China(No.2003AA430200)

The authors are with the College of Mechanical \& Electrical Engineering, Central South University, Changsha, China (e-mail:daqing_zh@163.com).

Address: the College of Mechanical \& Electrical Engineering, Central South University, Changsha, China, Postal address: 410083, telephone: 13755167425 fax: +86-731-4020612.

\section{INTRODUCTION}

A hydraulic excavator is a multi-functional construction machine. Workers in the construction industry use it for tasks such as excavating, dumping, finishing, lifting work, etc. However, operators who control hydraulic excavators must be trained for many years to do such work quickly and skillfully. A hydraulic excavator has three links: boom, dipper and bucket; and an operator have two arms. Thus, it is not easy for beginners to execute elaborate work that manipulates three links at the same time. Moreover, because the operators have to run work in various dangerous and dirty environments, the number of skillful operators is ever decreasing. For that reason, studying the automation of hydraulic excavators is necessary for improving productivity, efficiency, and safety [1] [2]. The automation of hydraulic excavators has been studied by several researchers in [1]-[6], and so on. Among the fundamental element used as a basis for developing more complicated tasks, the Control of excavator's arm is an important and basic task in autonomous research of hydraulic excavator at present, and this work is difficult from the standpoint of the following problems: parameter variations in mechanical structures, various nonlinearities in hydraulic actuators, and disturbance due to the contact with the ground. For such reasons difficulties exist in controlling a robotic excavator. To solve these problems, several research works have been performed, which may be categorized as either studies based on rules (for instance, in [3] [5]) or model base studies (for example, in [1] [2][4]). This paper presents a discontinuous projection based on an adaptive robust controller to approximate the nonlinear gain coefficient of the valve and the nonlinear of the whole system, the error is deal with robust feedback and an adaptive robust controller is designed. Finally, the experiment of the boom motion control is presented to illustrate the feasibility.

\section{OVERVIEW OF EXPERIMENT EXCAVATOR}

In this paper, a robotic excavator as a testbed is retrofitted based on the Sunward SWE85 hydraulic excavator, and the hydraulic system retrofitted can be shown in Fig.1. On the base of original hydraulic system, electrohydraulic pilot control has replaced hydraulic pilot control by adding proportional relief valves and substituting hydraulic pilot handle with electrical handle. Using the button on the electrical handle can switch between manual control and computer control. 


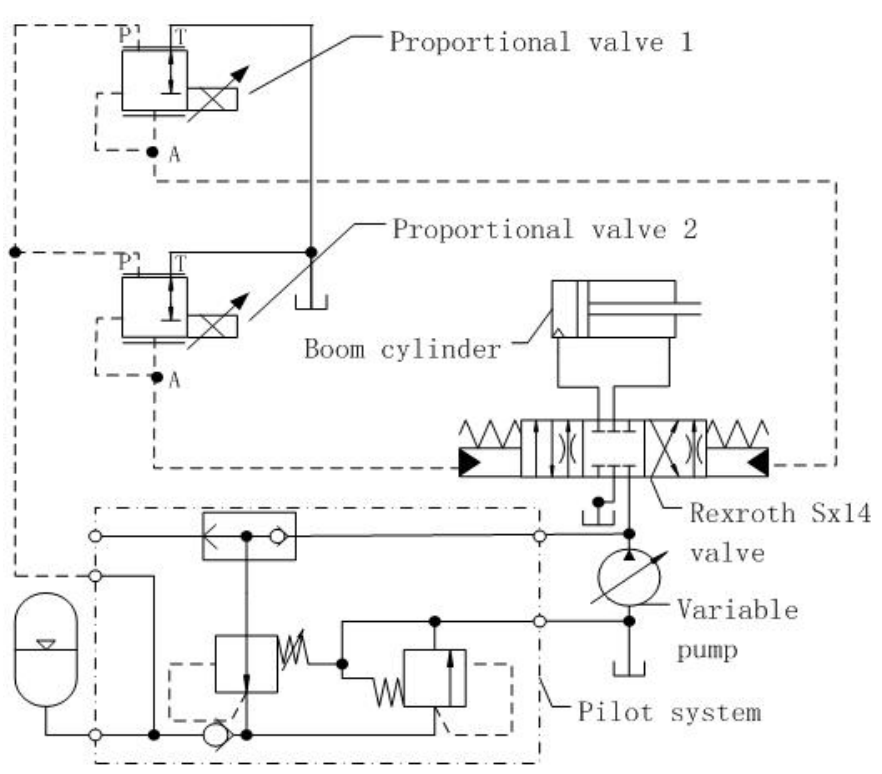

Fig. 1 The retrofitted electrohydraulic system of excavator ( boom cylinder)

The block diagram of hardware designed to control the robotic excavator is seen in Fig.2. The control system consists of two levels; the high-level (PC) controller computes reference angles corresponding to reference trajectories and transfers orders to low-level controller; According to these orders, the low-level controller implements position control by measuring the joints position and pressure of cylinders. That is, controlling the pilot valve to drive the cylinders according to the output current.

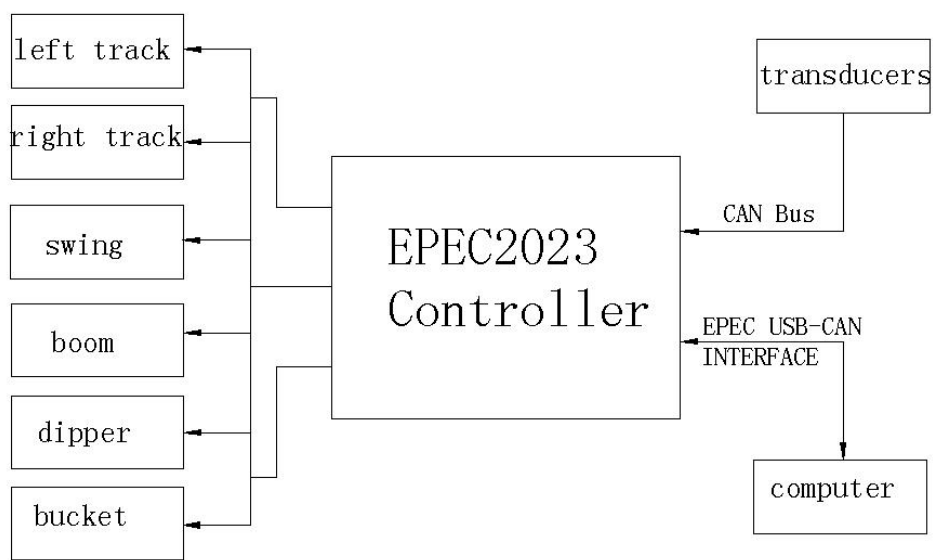

Fig.2 Hardware architecture of the control system

\section{MODEL OF ROBOTIC EXCAVATOR’S ARM}

The robotic excavator's arm is made up of low level controller, hydraulic actuator system and excavator's manipulator. The manipulator contains boom, dipper and bucket.

\section{A. The kinematic model of manipulator}

The aim of establishing the kinematic model of manipulator is to transfer bucket tip's reference trajectories to the corresponding and required reference angles sequence of each joint, and to get the motion sequences of hydraulic cylinders.

In the paper, the exponential product formula based on screw theory is used to develop the kinematic model of manipulator. One of the most attractive characteristic of exponential product formula is that it has two coordinate systems, one is base coordinate system $\mathrm{S}$ and the other is tool coordinate system $\mathrm{T}$ (details in Fig.3).

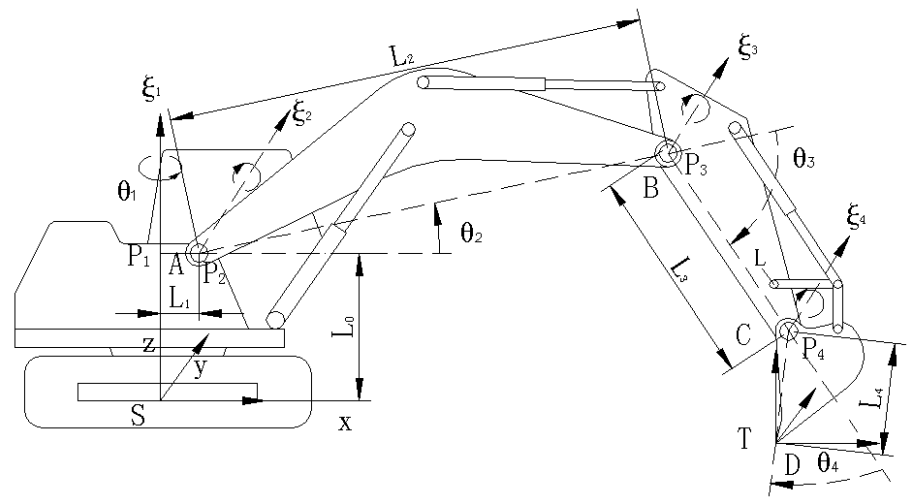

Fig.3 Kinematics model for working mechanism of hydraulic excavator

Given $\omega_{1}=\left[\begin{array}{lll}0 & 0 & 1\end{array}\right]^{\top}$, and

$\omega_{2}=\omega_{3}=\omega_{4}=\left[\begin{array}{lll}0 & 1 & 0\end{array}\right]^{\top}$, the motion screws of rotating joints are constructed as follows:

$\xi_{1}=\left[\begin{array}{llllll}0 & 0 & 0 & 0 & 0 & 1\end{array}\right]^{\top}, \xi_{2}=\left[\begin{array}{llllll}-I_{0} & 0 & I_{1} & 0 & 1 & 0\end{array}\right]^{\top}$,

$\xi_{3}=\left[\begin{array}{lllllll}-I_{0} & 0 & I_{1}+I_{2} & 0 & 1 & 0\end{array}\right]^{\top}$,

$\xi_{4}=\left[\begin{array}{llllll}-I_{0} & 0 & I_{1}+I_{2}+I_{3} & 0 & 1 & 0\end{array}\right]^{\top}$

Where $\omega_{\mathrm{i}} \in \mathfrak{R}^{3}(\mathrm{i}=1,2,3)$ are the unit vectors on the axes direction of motion screws. Then the rigid body transform $\mathrm{g}_{\mathrm{st}}(\theta)$ is gained relative to the base coordinate system as follows:

$\mathrm{g}_{\mathrm{st}}(\theta)=\left[\begin{array}{cccc}\mathrm{C}_{1} \mathrm{C}_{234} & -\mathrm{S}_{1} & \mathrm{C}_{1} \mathrm{~S}_{234} & \mathrm{C}_{1}\left(\mathrm{I}_{2} \mathrm{C}_{2}+\mathrm{I}_{3} \mathrm{C}_{23}+\mathrm{I}_{4} \mathrm{C}_{234}+\mathrm{I}_{1}\right) \\ \mathrm{S}_{1} \mathrm{C}_{234} & \mathrm{C}_{1} & \mathrm{~S}_{1} \mathrm{C}_{234} & \mathrm{~S}_{1}\left(\mathrm{I}_{2} \mathrm{C}_{2}+\mathrm{I}_{3} \mathrm{C}_{23}+\mathrm{I}_{4} \mathrm{C}_{234}+\mathrm{I}_{1}\right) \\ -\mathrm{S}_{234} & 0 & \mathrm{C}_{234} & \mathrm{I}_{0}-\left(\mathrm{I}_{2} \mathrm{~S}_{2}+\mathrm{I}_{3} \mathrm{~S}_{23}+\mathrm{I}_{4} \mathrm{~S}_{234}+\mathrm{I}_{1}\right) \\ 0 & 0 & 0 & 1\end{array}\right]$

Where $c_{1}=\cos \left(\theta_{1}\right), c_{234}=\cos \left(\theta_{2}+\theta_{3}+\theta_{4}\right)$,

$\mathrm{S}_{1}=\sin \left(\theta_{1}\right), \mathrm{S}_{234}=\sin \left(\theta_{2}+\theta_{3}+\theta_{4}\right)$.

$\mathrm{f}(\mathrm{t})$ is the reference trajectory of bucket, whose independent variable is $t$, and the reference position and orientation of bucket can be expressed by a rigid body transform in the base coordinate system. That is:

$$
f(t)=\left[\begin{array}{cccc}
n_{x} & s_{x} & a_{x} & p_{x} \\
n_{y} & s_{y} & a_{y} & p_{y} \\
n_{z} & s_{z} & a_{z} & p_{z} \\
0 & 0 & 0 & 1
\end{array}\right]
$$


Where $\mathrm{n}, \mathrm{S}, \mathrm{a}$ is orientation matrix, $\mathrm{P}$ is the position vector. The joint angles corresponding to the reference trajectory are obtained by resolving equation (3) (the detail calculating process in [7]).

$$
f(t)=g_{s t}(\theta(t))
$$

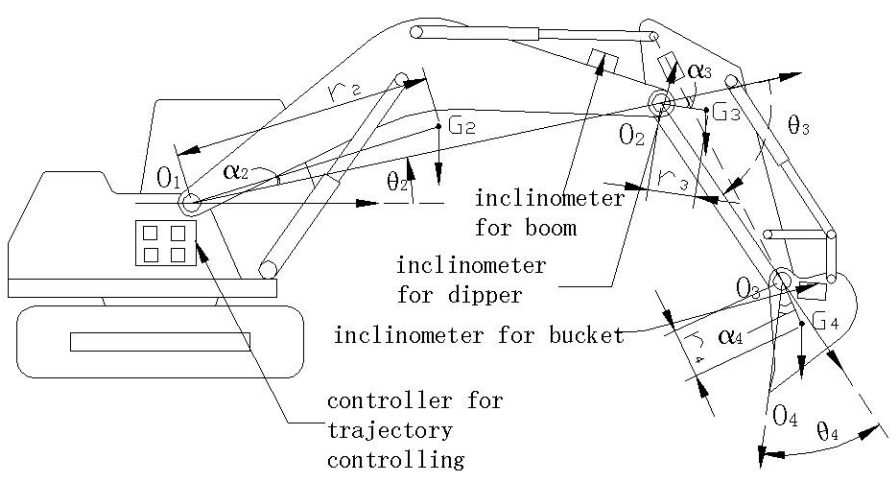

Fig.4 The diagram of manipulator and the position of controller and transducers on the excavator

\section{B. The dynamic model of manipulator}

Fig. 4 shows a schematic representation of the manipulator of hydraulic excavator with the assigned variables $\theta_{2}, \theta_{3}$ and $\theta_{4}$ for the boom, dipper and bucket joint angles, respectively. The cab swing angle $\left(\theta_{1}\right)$ is not shown in this figure, as it is not considered in this study. In Fig.4, $\mathrm{G}_{\mathrm{i}}$ if the center of gravity for link $\mathbf{i}$ expressed in polar coordinates $\left(r_{i}, \alpha_{i}\right)$ relative to the link $i$. The link angles with respect to the horizontal plane are $\theta_{2}$ for the boom, $\theta_{23}=\theta_{2}+\theta_{3}$ for the stick, and for the bucket, $\theta_{234}=\theta_{2}+\theta_{3}+\theta_{4}$. The dynamic model can be developed according to Lagrange equation. This paper takes boom as an example, and gives out the dynamic equation [8] - [12] of boom as follows:

$$
\begin{aligned}
& \left(D_{c}+m l_{e}^{2}\right) \theta_{2}^{\alpha}+G_{c}\left(\theta_{2}\right)+m g l_{g}\left(\theta_{2}\right) \\
& =\frac{\partial y}{\partial \theta_{2}}\left(P_{1} A-P_{2} A_{2}\right)-T\left(t, \theta_{2}, \theta_{2}^{\alpha}\right) \\
& D_{c}=I_{2}+m_{2} r_{2}^{2}+\left(m_{3}+m_{4}\right) l_{2}^{2}+m_{3} l_{2} r_{3} \cos \left(\theta_{4}+\alpha_{3}\right) \\
& +\mathrm{I}_{3}+\mathrm{mr}_{3}^{2}+\mathrm{m}_{4} \mathrm{l}_{3}^{2}+\mathrm{I}_{4}+\mathrm{m}_{4} \mathrm{r}_{4}^{2}+2 \mathrm{~m}_{4} \mathrm{l}_{2} \mathrm{I}_{3} \mathrm{c}_{3} \\
& +2 m_{4} l_{3} r_{4} \cos \left(\theta_{4}+\alpha_{4}\right)+2 m_{4} l_{2} r_{4} \cos \left(\theta_{34}+\alpha_{4}\right) \\
& \mathrm{G}_{\mathrm{c}}=\mathrm{m}_{2} \mathrm{gr}_{2} \cos \left(\theta_{2}+\alpha_{2}\right)+\left(\mathrm{m}_{3}+\mathrm{m}_{4}\right) \mathrm{gl}_{2} \cos \theta_{2} \\
& +m_{3} g r_{3} \cos \left(\theta_{23}+\alpha_{3}\right)+m_{4} g\left(l_{3} \cos \left(\theta_{23}\right)\right. \\
& \left.+r_{4} \cos \left(\theta_{234}+\alpha_{4}\right)\right), I_{g}=I_{2} C_{2}+I_{3} C_{23}+I_{4} C_{234} \text {, } \\
& \mathrm{I}_{\mathrm{e}}^{2}=\left(\mathrm{I}_{2} \cos \theta_{2}+\mathrm{I}_{3} \cos \theta_{23}+\mathrm{I}_{4} \cos \theta_{234}\right)^{2} \\
& +\left(\mathrm{I}_{2} \sin \theta_{2}+\mathrm{I}_{3} \sin \theta_{23}+\mathrm{I}_{4} \sin \theta_{234}\right)^{2}, \mathrm{i}=2,3,4
\end{aligned}
$$

Where $P_{1}$ and $P_{2}$ are the pressure of the boom cylinder at the head-side and rod-side respectively. $A_{1}$ and $A_{2}$ are the areas of pistons on two sides. $T\left(t, \theta_{2}, \theta_{2}^{\alpha}\right)$ is the total disturbed moment including moment of load and friction. $I_{2}, I_{3}, I_{4}$ are moment of inertia of boom, dipper and bucket relative to center of mass of it's own respectively. $m_{2}, m_{3}, m_{4}$ are mass of boom, dipper, and bucket respectively. $m$ is the mass of unknown load in bucket.

\section{The model of electro-hydraulic proportional system}

\section{1) The hydraulic cylinder equation of continuity}

The driving cylinders of the manipulator of hydraulic excavator are control by Rexroth SX14 valve. The driving cylinders of the manipulator of hydraulic excavator are control by Rexroth SX14 valve. The orifice size of directional valve is decided by output pressure of proportional relief valve, which is decided by the output current of controller. Hydraulic system model can be seen in Fig.5.

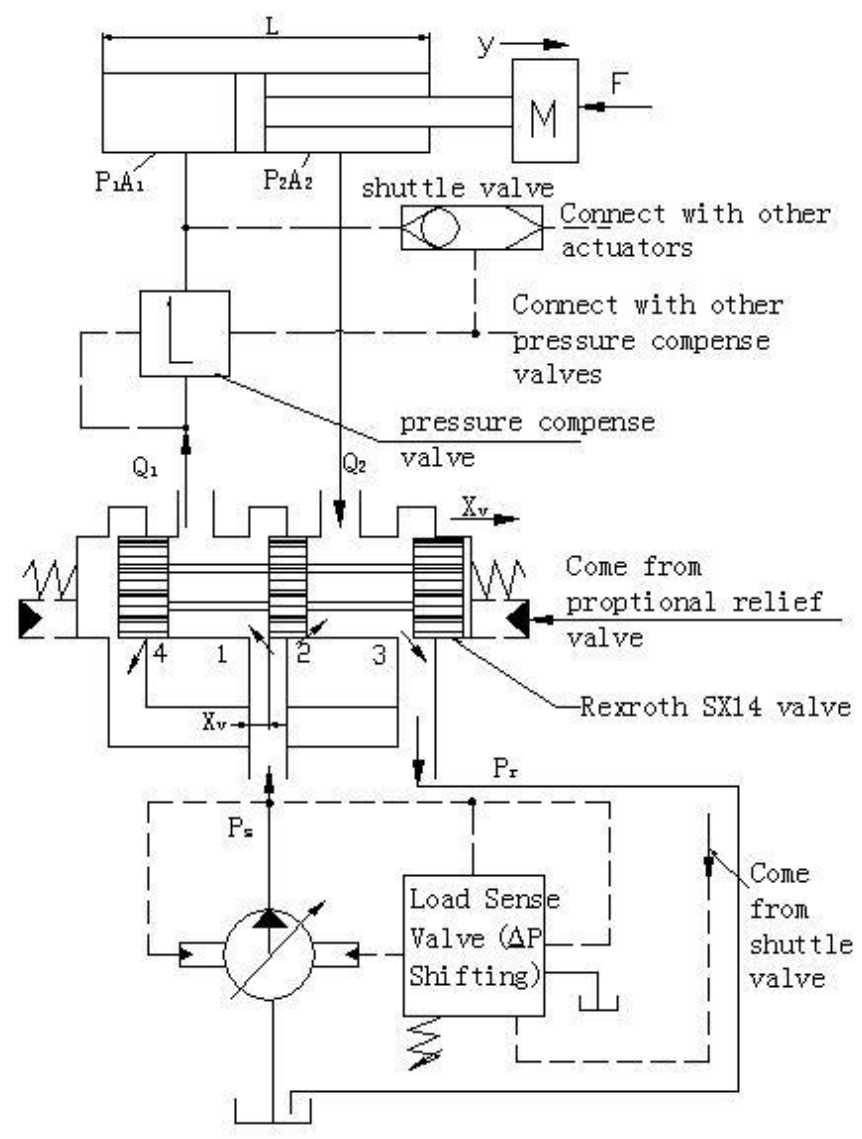

Fig.5 The diagram of LUDV hydraulic system after retrofitting

Following is a summary of the assumption that has been made in developing the model of a hydraulic cylinder:

1) The proportional valve is a symmetrical 3-way and 4-port valve. The dead band of valve is also symmetrical, and the flow in it is turbulent. 
2) Possible dynamic behavior of the pressure in the transmission lines between valve and actuator is assumed to be negligible.

3) Pressure is equal everywhere in one volume of hydraulic cylinder, and the temperature and the bulk modulus are constants.

4) The leakage of flows is laminar.

The continuous equation [13] of compressible oil is given as follows:

$$
\sum Q_{\text {in }}-\sum Q_{\text {out }}=\frac{d V}{d t}+\frac{V}{\beta} \bullet \frac{d P}{d t}
$$

Here $\mathrm{V}$ is the initial volume of liquid subjected to compression. $\mathrm{dV}$ and $\mathrm{dP}$ are the changes in pressure and volume respectively. $\sum \mathrm{Q}_{\mathrm{in}}$ is the input flows of liquid, and $\sum \mathrm{Q}_{\text {out }}$ is the output flows of liquid. $\beta$ is the bulk modulus.

Considering the internal and external leakage of cylinder, the equation (6) and (7) are can be developed from equation (5) as follows:

$Q_{1}-C_{i c}\left(P_{1}-P_{2}\right)-C_{e c} P_{1}=\frac{d V_{1}}{d t}+\frac{V_{1}}{\beta_{e}} \bullet \frac{d P_{1}}{d t}$

$C_{i c}\left(P_{1}-P_{2}\right)-Q_{2}-C_{e c} P_{2}=\frac{d V_{2}}{d t}+\frac{V_{2}}{\beta_{e}} \bullet \frac{d P_{2}}{d t}$

Where $Q_{1}$ and $Q_{2}$ are the supplied and return flow to the

cylinder respectively. $\mathrm{C}_{\mathrm{ic}}$ is the internal leakage

coefficient. $\mathrm{C}_{\mathrm{ec}}$ is the external leakage coefficient. $\beta_{e}$ is the effective bulk modulus(including liquid, the air in oil and so on). $\mathrm{V}_{1}, \mathrm{~V}_{2}$ are the volume of fluid flow to and from the hydraulic cylinder. $\mathrm{V}_{1}, \mathrm{~V}_{2}$ can be got as follows:

$$
\mathrm{V}_{1}=\mathrm{V}_{01}+\mathrm{A}_{1} \mathrm{y}, \quad \mathrm{V}_{2}=\mathrm{V}_{02}-\mathrm{A}_{2} \mathrm{y}
$$

Where $V_{01}$ is the initial volume of cylinder side which the fluid flows into. $V_{02}$ is the initial volume of cylinder side from which the fluid flows out. $\mathrm{Y}$ is the displacement of piston. So the equation (9) can be given as:

$$
\frac{\mathrm{dV}_{1}}{\mathrm{dt}}=\mathrm{A}_{1} \frac{\mathrm{dy}}{\mathrm{dt}}, \quad-\frac{\mathrm{dV}_{2}}{\mathrm{dt}}=\mathrm{A}_{2} \frac{\mathrm{dy}}{\mathrm{dt}}
$$

The external leakage is the leakage between the piston rod and external seals. Because external leakage on the construction machine is forbidden, and external leakage is disappear with the development of sealing technology. The influence of external leakage is neglected in this paper. $\mathrm{y}$ can be expressed as a function of $\theta_{2}$. Then equation (6) and (7) can be rebuilt as:

$\dot{P}_{1}=\frac{\beta_{e}}{V_{1}}\left[Q_{1}-C_{i c}\left(P_{1}-P_{2}\right)-A_{1} \frac{\partial y}{\partial \theta_{2}} \dot{\theta}_{2}\right]$

$\dot{P}_{2}=\frac{\beta_{e}}{V_{2}}\left[C_{i c}\left(P_{1}-P_{2}\right)-Q_{2}+A_{2} \frac{\partial y}{\partial \theta_{2}} \dot{\theta}_{2}\right]$

Where $C_{i c}$ is assumed to be a constant to simplify the system model.

\section{2) The flow equation of electro-hydraulic proportional valve}

In this paper, Load Independent Flow Distribution (abbreviated to LUDV) hydraulic system is adopted on the experimental robotic excavator. According to the theory of LUDV system [14], the flow equation can be gotten as follows:

$Q_{1}=C_{d} W X_{v} \sqrt{\frac{2}{\rho} \Delta P_{1}}=\left\{\begin{array}{l}C_{d} W K_{I} I(t) \sqrt{\frac{2}{\rho} \Delta P}, I(t) \geq 0 \\ -C_{d} W K_{I} I(t) \sqrt{\frac{2}{p}\left(P_{1}-P_{r}\right)}, I(t)<0\end{array}\right.$

$Q_{2}=C_{d} W X_{v} \sqrt{\frac{2}{p} \Delta P_{2}}=\left\{\begin{array}{l}-C_{d} W K_{I} I(t) \sqrt{\frac{2}{p}\left(P_{2}-P_{r}\right)}, I(t) \geq 0 \\ C_{d} W K_{I} I(t) \sqrt{\frac{2}{p} \Delta P}, I(t)<0\end{array}\right.$

Where $\mathrm{P}_{r}$ is the pressure of return oil. $\Delta \mathrm{P}$ is the pressure of spring of load sense valve. $C_{d}$ is the flow gain coefficient. $W$ is the area gradient of orifice. $\mathrm{X}_{\mathrm{v}}$ is the displacement of spool. $\rho$ is the density of oil. $\mathbf{K}_{\mathrm{I}}$ is the current gain of proportional valve. $\mathrm{l}(\mathrm{t})$ is the control current of proportional valve.

In this paper, the proportional direction control valve has a quite large dead band, which is due to the close centered valve configuration. $C_{d}$ is proved to be nonlinear by experiment [15]. The net actual valve opening $X_{\text {nav }}$ can be defined as

$$
x_{\text {nav }}= \begin{cases}x_{v}-x_{d} & , x_{v}>x_{d} \\ 0 & ,-x_{d} \leq x_{v} \leq x_{d} \\ x_{v}+x_{d} & , x_{v}<-x_{d}\end{cases}
$$

Where $X_{d}$ is the dead band of valve.

The actual experimental test results reveal the nonlinear flow gain in the Fig.6, and the flow gain coefficient of valve can be approximated by two lines to simplify the model. To be controlled conveniently, $\mathrm{Q}$ (the flow of valve) can be expressed 
as equation (15) and (16).

$$
\begin{aligned}
& \mathrm{Q}\left(\mathrm{x}_{\mathrm{v}}, \Delta \mathrm{P}\right)=\mathrm{Q}_{\mathrm{M}}\left(\mathrm{x}_{\mathrm{v}}, \Delta \mathrm{P}\right)+\tilde{\mathrm{Q}}\left(\mathrm{x}_{\mathrm{v}}, \Delta \mathrm{P}\right) \\
& \mathrm{Q}_{1 \mathrm{M}}=\mathrm{C}_{\mathrm{d} 1} \mathrm{Wf}_{1}\left(\Delta \mathrm{P}_{1}\right) \mathrm{x}_{\text {nav }} \\
& \mathrm{Q}_{2 \mathrm{M}}=\mathrm{C}_{\mathrm{d} 2} \mathrm{Wf}_{2}\left(\Delta \mathrm{P}_{2}\right) \mathrm{x}_{\text {nav }}
\end{aligned}
$$

where $Q_{M}$ represent certain simplified flow mapping function that will be used in the controller design. $\tilde{Q}$ is the model error of the flow projection, and will be treated by robust feed back . Generally speaking, $C_{\mathrm{d} 1}$ and $\mathrm{C}_{\mathrm{d} 2}$ are constant for one working state.

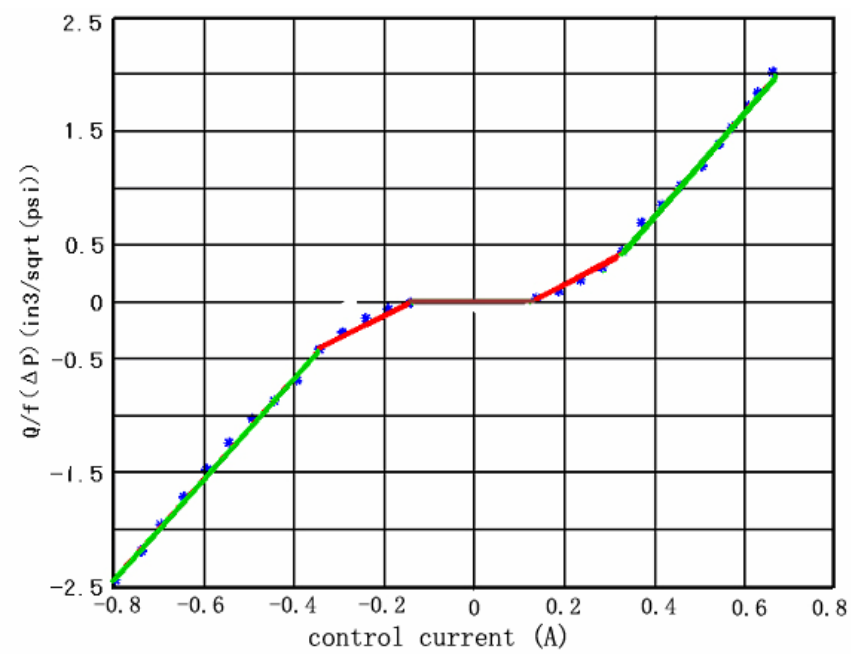

Fig.6 nonlinear characteristic flow gain of the proportional valve

\section{THE ADAPTIVE ROBUST CONTROLLER}

According to the model of excavator, the main difficulties to control the robotic excavator are that:(1)the dynamic of system is strongly nonlinear; (2) parameters of system are uncertain, for example, the uncertainty of $\mathrm{m}, \beta_{e}$ ( valid bulk modulus) and $\mathrm{T}_{\mathrm{n}}$ (the total disturb of system) which is brought by external disturb and un-modeled friction.

In this paper, the nonlinearity and uncertainty of parameters are treated by a discontinuous projection based on an adaptive robust controller [9]. In Fig.6, the line is used to compensate for the dead band of vale, which is the symmetrical line of plus curve based on the axis that is through the coordinate origin and make an angle of 458with the $\mathrm{x}$ axis. The flow projection error is compensated by robust feed back. $\mathrm{M}, \beta_{e}$ and $\mathrm{T}_{\mathrm{n}}$ are mainly considered as

$q_{1}=\frac{1}{1+\left(l_{e} / D_{c}\right) m}, q_{2}=\frac{T_{n}}{D_{c}+m_{e}^{2}}, q_{b}=\beta_{e}$, and $q=\left[q_{1}, q_{2}, q_{3}\right]^{\top}$ is defined as unknown parameter set. Then equation (4), (10) and (11) can be transform to equation (17).

$$
\begin{aligned}
\sigma_{2}= & \frac{q_{1}}{D_{c}}\left[\frac{\partial y}{\partial \theta_{2}}\left(P_{1} A-P_{2} A_{2}\right)-G_{c}\left(\theta_{2}\right)\right] \\
& +\frac{q_{1}}{l_{e}^{2}} g_{g}-\frac{1}{l_{e}^{2}} g_{g}+q_{2}+\tilde{T}\left(t, \theta_{2}, \theta_{2}^{\alpha}\right),
\end{aligned}
$$

$$
\begin{aligned}
& P_{1}^{\alpha}=\frac{q_{3}}{V_{1}}\left(-C_{i c}\left(P_{1}-P_{2}\right)-A \frac{\partial y}{\partial \theta_{2}} \theta_{2}^{\alpha}+Q_{1 M}+\tilde{Q}_{1}\right) \text {, } \\
& \mathrm{P}_{2}^{\mathrm{\alpha}}=\frac{\mathrm{q}_{3}}{\mathrm{~V}_{2}}\left(\mathrm{~A}_{2} \frac{\partial \mathrm{y}}{\partial \theta_{2}} \theta_{2}^{\alpha}-\mathrm{Q}_{1 \mathrm{M}}-\widetilde{\mathrm{Q}}_{2}+\mathrm{C}_{\mathrm{ic}}\left(\mathrm{P}_{1}-\mathrm{P}_{2}\right)\right)
\end{aligned}
$$

Where, $\tilde{\mathrm{T}}=\frac{\mathrm{T}\left(\mathrm{t}, \theta_{2}, \theta_{2}^{\alpha}\right)-\mathrm{T}_{\mathrm{n}}}{\mathrm{D}_{\mathrm{c}}+\mathrm{ml}_{\mathrm{e}}^{2}}, \mathrm{q}_{\min } \leq \mathrm{q} \leq \mathrm{q}_{\max }$,

$|\tilde{T}| \leq \delta_{\mathrm{T}},\left|\tilde{\mathrm{Q}}_{1}\right| \leq \delta_{\mathrm{Q} 1},\left|\tilde{\mathrm{Q}}_{2}\right| \leq \delta_{\mathrm{Q} 2}$, and $\mathrm{q}_{\min }, \mathrm{q}_{\max }, \delta_{\mathrm{T}}$,

$\delta_{\mathrm{Q} 1}$ and $\delta_{\mathrm{Q} 2}$ are known number. It is assumed that $\hat{\mathrm{q}}$ and $\widetilde{\mathrm{q}}$ are the estimated value and estimated error of qrespectively. Equation (18) is the adaptation law structure needed.

$$
\dot{\hat{q}}=\operatorname{Pr} o j_{\hat{\theta}}(\Gamma \tau)
$$

Where $\Gamma$ is the diagonal matrix. $\tau$ the adaptive function. $\operatorname{Pr} 0 \mathbf{j}_{\hat{\theta}}(\bullet)$ is the discontinuous projection [16].

According to the above work of this paper, the following task must be undertaken.

Step 1

Defining $P_{L}=P_{1} A-P_{2} A_{2}, P_{L}$ can be treated as the input of equation (17) . The goal of this step is to get a virtual control law $P_{L d}$ for $P_{L}$ so that output error $Z_{1}=\theta_{2}-\theta_{2 d}$ can converge to zero to get high trajectory tracking accuracy. Assuming that $\theta_{2 r}^{\alpha}=\theta_{2 d}^{\alpha}-k_{1} z_{1}, \theta_{2 r}^{\alpha}=\theta_{2 d}^{\alpha}-k_{1} \frac{\alpha}{\alpha}$,

$z_{2}=\dot{\theta}_{2}-\dot{\theta}_{2 r}, \phi_{2}=\left[\frac{1}{D_{c}}\left(\frac{\partial y}{\partial \theta_{2}} P_{L d a}-G_{c}\right)+g \frac{l_{g}}{l_{e}^{2}}, 1,0\right]^{T}$ and according to function of Lyapunov, the following equation can be gained.

$$
\begin{gathered}
P_{L d}=P_{L d a}+P_{L d s}, \quad \tau_{2}=\phi_{2} z_{2} \\
P_{L d a}=\frac{\partial \theta_{2}}{\partial y}\left[G_{c}\left(\theta_{2}\right)+\frac{D_{c}}{q_{1}}\left(-g \frac{\hat{q}_{1}}{l_{e}^{2}} l_{g}+g \frac{1}{l_{e}^{2}} l_{g}-\hat{q}_{2}+\ddot{q}_{2 r}\right)\right] \\
P_{L d s}=P_{L d s 1}+P_{L d s 2} \\
P_{L d s 1}=-\frac{D_{c}}{q_{1 \min }} \frac{\partial \theta_{2}}{\partial y}\left(k_{2 s 1}+k_{2}\right) z_{2}, k_{2}>0
\end{gathered}
$$

Where $k_{2 s 1}$ is a control gain to be synthesized later, $P_{L d s 2}$ is any function satisfying the following conditions

Condition1 $z_{2}\left[\frac{1}{D_{c}} q_{1} \frac{\partial y}{\partial \theta_{2}} P_{L d s 2}-\widetilde{q}^{T} \phi_{2}+\widetilde{T}\right] \leq \varepsilon_{2}$

Condition $2 z_{2} \frac{\partial y}{\partial \theta_{2}} P_{L d s 2}, \varepsilon_{2}>0$ 
Step 2

$Z_{3}=P_{L}-P_{L d}$ is assumed to be an error of input then the actual controlling principle will be developed to make $Z_{3}$ approximate to zero. According to equation (17) , (19), the equation (21) can be given as follows:

$\underset{z}{\alpha}=P_{L}^{\alpha}-P_{L d}^{\alpha}=q_{3}\left[-\left(\frac{A_{1}^{2}}{V_{1}}+\frac{A_{2}^{2}}{V_{2}}\right) \frac{\partial y}{\partial \theta_{2}} \theta_{2}^{\alpha}\right.$

$\left.+\left(\frac{A_{1}}{V_{1}} Q_{1 M}+\frac{A_{2}}{V_{2}} Q_{2 M}\right)+\left(\frac{A_{1}}{V_{1}} \tilde{Q}_{1}+\frac{A_{2}}{V_{2}} \tilde{Q}_{2}\right)\right]-P_{L d c}^{\alpha_{d}}-P_{L d u}^{\mathscr{L}}$

Where $P_{L d c}^{\alpha}=\frac{\partial P_{L d}}{\partial \theta_{2}} \theta_{2}^{\&}+\frac{\partial P_{L d}}{\partial \theta_{2}^{\alpha}} \theta_{2}^{\alpha}+\frac{\partial P_{L d}}{\partial t}$ is the calculable

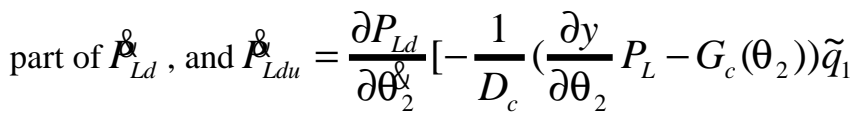
$\left.-\frac{1}{l_{\mathrm{e}}^{2}} \mathrm{gl}_{\mathrm{g}} \widetilde{\mathrm{q}}_{1}-\widetilde{\mathrm{q}}_{2}+\tilde{\mathrm{T}}_{]}\right]+\frac{\partial \mathrm{P}_{\mathrm{Ld}}}{\partial \mathrm{q}} \mathcal{Q}^{\mathrm{d}}$ is the error part of $\mathbb{L d}_{\mathrm{Ld}}$.this error part is treated by robust feedback method. $\frac{A_{1}}{V_{1}} Q_{1 M}+\frac{A_{2}}{V_{2}} Q_{2 M}=Q_{L}$ is considered as a valid input in equation (21). In this process, $Q_{L d}$ which is the valid input of $\mathrm{Q}_{\mathrm{L}}$ must be developed to make $\mathrm{P}_{\mathrm{L}}$ track $\mathrm{P}_{\mathrm{Ld}}$ which is developed in step (1). So $\mathrm{Q}_{\mathrm{Ld}}$ (controlling function) and $\tau_{3}$ (adaptive function) can be given respectively as follows:

$\mathrm{Q}_{\mathrm{Ld}}\left(\theta_{2}, \theta_{2}^{\alpha}, \mathrm{P}_{1}, \mathrm{P}_{2}, \hat{\mathrm{q}}, \mathrm{t}\right)=\mathrm{Q}_{\mathrm{Lda}}+\mathrm{Q}_{\mathrm{Lds}} \tau_{3}=\tau_{2}+\phi_{3} z_{3}$

$\mathrm{Q}_{\mathrm{Lda}}=-\frac{1}{\mathrm{q}_{\mathrm{B}}} \mathrm{Q}_{\mathrm{Lde}}, \mathrm{Q}_{\mathrm{Lds}}=\mathrm{Q}_{\mathrm{Lds} 1}+\mathrm{Q}_{\mathrm{Lds} 2}$,

$Q_{\text {Lds1 }}=-\frac{1}{q_{3 \text { min }}}\left(k_{3}+k_{3 s 1}\right) z_{3}, k_{3}>0$

Where ,

$$
\begin{aligned}
\mathrm{Q}_{\mathrm{Lde}} & =\frac{1}{\mathrm{D}_{\mathrm{c}}} \frac{\partial \mathrm{y}}{\partial \theta_{2}} \mathrm{z}_{2} \hat{\mathrm{q}}_{1}-\hat{\mathrm{q}}_{\mathrm{B}}\left(\frac{\mathrm{A}^{2}}{\mathrm{~V}_{1}}+\frac{\mathrm{A}_{2}^{2}}{\mathrm{~V}_{2}}\right) \frac{\partial \mathrm{y}}{\partial \theta_{2}} \theta_{2}^{\alpha}-\mathrm{P}_{\mathrm{Ldc}}, \\
\phi_{3}= & {\left[\frac{1}{D_{c}} \frac{\partial y}{\partial \theta_{2}} z_{2}-\frac{\partial P_{L d}}{\partial \dot{\theta}_{2}}\left[\frac{1}{D_{c}}\left(\frac{\partial y}{\partial \theta_{2}} P_{L}-G_{c}\left(\theta_{2}\right)\right)\right.\right.} \\
+ & \left.\left.\frac{1}{\mathrm{I}_{\mathrm{e}}^{2}} \mathrm{gl}_{\mathrm{g}}\right], \frac{-\partial \mathrm{P}_{\mathrm{Ld}}}{\partial \theta_{2}^{\alpha}},-\left(\frac{\mathrm{A}_{1}^{2}}{\mathrm{~V}_{1}}+\frac{\mathrm{A}_{2}^{2}}{\mathrm{~V}_{2}}\right) \frac{\partial \mathrm{y}}{\partial \theta_{2}} \theta_{2}^{\alpha}+\mathrm{Q}_{\mathrm{Lda}}\right]^{\top}
\end{aligned}
$$

Where $k_{3 s 1}$ is a control gain to be synthesized later, $P_{L d s 2}$ is any function satisfying the following conditions:

Condition $1 z_{3}\left[q_{3} P_{L d s 2}+q_{3} \widetilde{Q}_{L}-\widetilde{q}^{T} \phi_{3}-\frac{\partial P_{L d}}{\partial \theta_{2}} \widetilde{T}\right] \leq \varepsilon_{3}$

Condition $2 z_{3} Q_{\text {Lds } 2}, \varepsilon_{3}>0$

After $Q_{L d}$ being gained, the valid displacement of spool can be computed according to equation (12), (13) and (16) as follows:

$$
\mathrm{x}_{\text {nav }}=\frac{\mathrm{Q}_{\mathrm{Ld}}\left(\theta_{2}, \theta_{2}^{\mathcal{Q}}, \mathrm{P}_{1}, \mathrm{P}_{2}, \hat{\mathrm{q}}, \mathrm{t}\right)}{\frac{\mathrm{A}_{1}}{\mathrm{~V}_{1}} \mathrm{C}_{\mathrm{d} 1} \mathrm{f}_{1}\left(\Delta \mathrm{P}_{1}\right)+\frac{\mathrm{A}_{2}}{\mathrm{~V}_{2}} \mathrm{C}_{\mathrm{d} 2} \mathrm{f}_{2}\left(\Delta \mathrm{P}_{2}\right)}
$$

$X_{v}$ is assumed to be proportionable to $I(t)$, that is ,

$$
\mathrm{X}_{v}=\mathrm{KI}(\mathrm{t}) \text {, then }
$$

$$
I(t)=K x_{v}= \begin{cases}K\left(x_{\text {nav }}+x_{d}\right) & , x_{\text {nav }}>0 \\ 0 & , x_{\text {nav }}=0 \\ K\left(x_{\text {nav }}-x_{d}\right) & , x_{\text {nav }}<0\end{cases}
$$

Assuming $\tau=\tau_{3}$ in equation (18), $\mathrm{k}_{2 \mathrm{sl}}$ and $\mathrm{k}_{3 \mathrm{sl}}$ are selected to make

$$
k_{2 s 1} \geq \frac{1}{2}\left\|\Gamma \phi_{2}\right\|^{2}, k_{3 s 1} \geq\left\|\partial P_{L d} / \partial \hat{q}_{2}\right\|^{2}+\frac{1}{2}\left\|\Gamma \phi_{2}\right\|^{2}
$$

As a result, high accuracy can be achieved by using equation (25) as a controlling principle.

\section{EXPERIMENT AND CONCLUSION}

The motion controlling experiment of boom is done on the robotic excavator, which is based on the Sunward SWE85 excavator. It is assumed that the reference angle is a sine curve, whose amplitude is 40 degrees, and whose center line is -2 degree. The experimental result is showed in Fig.7. The result exhibits good tracking performance for boom cylinder under the controller developed in this paper. The peak error is less than 4 degrees.

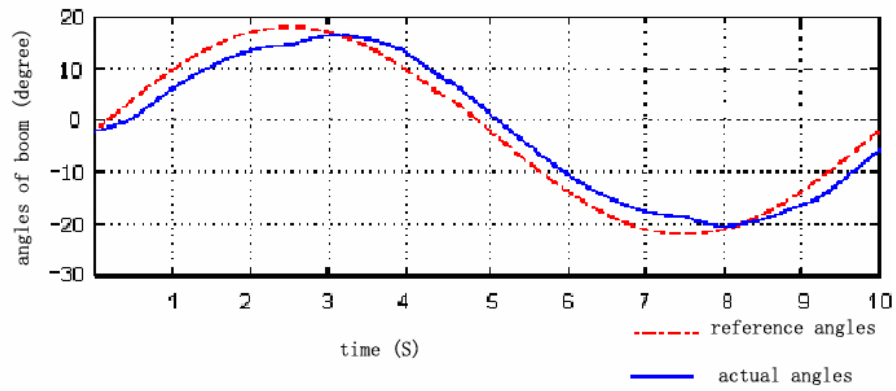

Fig.7 experiment of the boom's angle control

The motion control of hydraulic excavator is the base to achieve automatic excavation. The motion control principle is developed in this paper, under which good tracking performance can be gained. So base on the work done in this paper, the telecontrol of excavator can be realized if communication system is developed; and automatic excavation can be achieved if the trajectory programming is completed.

Appendix: 


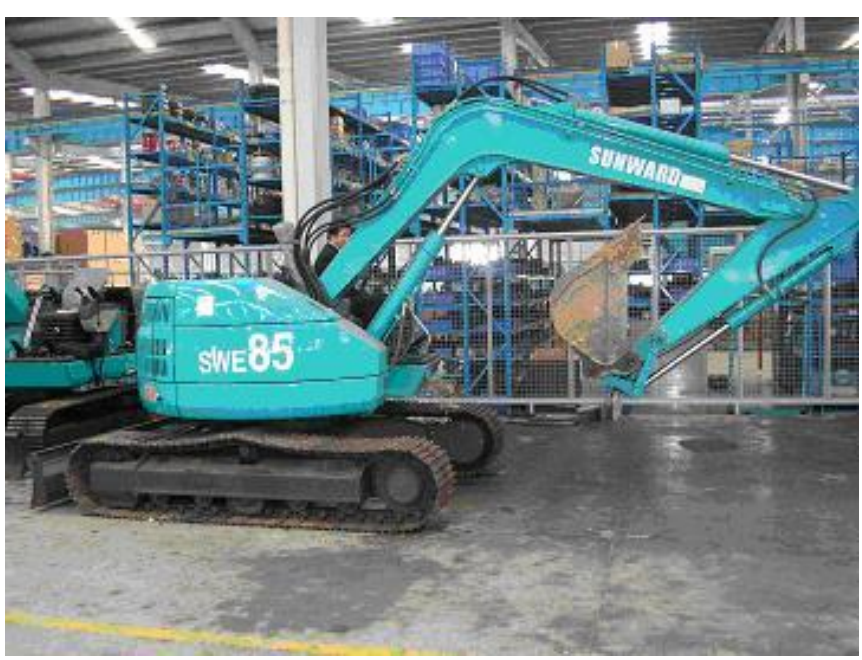

Fig. 8 The experimental robotic excavator based on Sunward SWE85 excavator

Acknowledgment

The author would like to thank all those students, research associates who have contributed to the development of the robotic excavator in this paper. In addition they would like to thank the assistance given by the company: Sunward Intelligent Machine Corporation.

\section{REFERENCES}

[1] Sung-Uk Lee, Pyung Hun Chang, Control of a heavy-duty robotic excavator using time delay Control with switching action with integral sliding surface, Proceeding of the 2001 IEEE international conference on Robotics \& Automation, Seoul, Korea, May 21-26, 2001, pp.3955-3960

[2] Sung-Uk Lee, Pyung Hun Chang, Control of a heavy-duty robotic excavator using time delay Control with integral sliding surface, Control Engineering Practice 10(2002), pp.697-711

[3] Bradley D, Seward D, the development, control and operation of an autonomous robotic excavator [J], Journal of Intelligent and Robotic Systems, 1998, 21:73-97.

[4] Nguyen Hong Quang, Robust low level control of robotic excavation, $\mathrm{Ph} . \mathrm{D}$. dissertation, University of Sydney. March 2000

[5] Patrick Sean Rowe, Adaptive motion planning for autonomous mass excavation, Ph.D. dissertation, Carnegie Mellon University, January 1999

[6] Masakazu Haga, Watanabe Hiroshi, Kazuo Fujishima, Digging control system for hydraulic excavator, Mechatronics 11 (2001), pp.665-676

[7] Zhang Zhi Wen, Zhang Da Qing, Shi Sheng Xian and Cheng Yong, The Analysis of Excavator Kinematics based on the Exponential Product Formula. Modern Machine, to be published

[8] A. J. Koivo, M. Thoma, E.Kocaoglan, and J. Andrade-Cetto, Modeling and control of excavator dynamics during digging operation, Journal of aerospace engineering 1996.1, pp.10-18

[9] FanpingBu and BinYao, Nonlinear Adaptive Robust Control of Hydraulic Actuators Regulated by Proportional Directional Control Valves with Dead band and Nonlinear Flow Gains, Proceedings of the American Control Conference Chicago, Illinois June 2000,pp.4129-4133

[10] Shahram Tafazoli, Peter D. Lawrence, and S.E. Salcudean, Identification of inertial and friction parameters for excavator arms, IEEE transactions on robotics and automation, VOL.15 NO.5 OCT 1999, pp.966-971

[11] Wang Jian Zhi, Research on the working condition monitoring and automatic operation for hydraulic excavator, Master. Dissertation, Zhe Jiang University, January 1997

[12] FanpingBu and BinYao, Observer based coordinated adaptive robust control of robot manipulator driven by single-rod hydraulic actuators, Proceeding of the 2000 IEEE international conference on Robotics \& Automation San Francisco, CA. April 2000

[13] Li HongRen, hydraulic controlling system, Defense industry publishing company, 1981.6, pp.59-60
[14] Chen Qian Gen, Ji Yun Feng, Wu Wang Rong, Load independent flow distribution control system, Hydraulic and Pneumatic, 2003.10, pp.10-11

[15] Yao B. High performance adaptive robust control of nonlinear systems: a general framework and new schemes [A]. In: Proceeding of IEEE Conference on Decision and Control[C], 1997,pp.2489-2494

[16] B.Yao and M. Tomizuka, Smooth robust adaptive sliding mode control of robot manipulators with guaranteed transient performance, in Proc. of American Control Conference, pp. 1176-1180 